\title{
Cognitive and Collateral— $—$ The Psychological Inheritance of the Gods' Culture, the Connection Context and the Establishment of the Art of Bird
}

\author{
Hua Li, Yulong Duan \\ Art College of Sichuan University, Chengdu, Sichuan, China, 610000
}

Keywords: Cognitive and Collateral, Inheritance, Gods' Culture, Connection Context, Establishment, Art of Bird

\begin{abstract}
The origin of human and "birds", bird image as a human art culture creation of the reference system. Flowers and birds, birds, birds, birds, birds, birds, birds, birds, birds, birds, birds, birds, birds, birds, birds, birds, birds) Birds show ... ... are all human and "birds" associated with the bird image of the theme of culture and arbitrary artistic aesthetic intentions. The artistic theme of bird image is a manifestation of the structure and thinking structure of the ancestors. Bird image from the totem into a pattern can be understood as the human from the myth thinking to aesthetic thinking deduction of a process. With the passage of time, the myth is not annihilated, it is in the process of human evolution is built into an aesthetic thinking. The establishment of the aesthetic relationship of the avalanche image becomes the link between the mythological thinking and the aesthetic thinking.
\end{abstract}

\section{The Symbolic of the Natural Enlightenment: The Psychological Identity and Inheritance of God Bird Culture}

God image is inspired by the natural enlightenment and thus to show the art form. "Bird in the fly" is the same human psychological awareness. God birds in the fly, the soul of the return of the ancient human beings always have "heavenly worship", "wings worship" of the deification of the plot. Flying birds and animals in the myth of the image, all countries exist and produce a certain degree of acceptance and national innovation:

According to the "Shan Hai Jing" in the geographical orientation of the deduction, the Bird's Bird's Look has been throughout the Yellow River and the Yangtze River Basin. "There are birds Yan ... ... said," the use of its feather clothing can avoid lightning. "There are birds Yan ... ... said the number of Sri Lanka," eating this bird will be epilepsy. "There are birds Yan ... ... called the parrot", this bird doctrine. There are birds Yan ... ... called green farming", this bird has the effect of the plague, but auspicious of the trillion. "There are birds Yan ... ... name", this bird can be the Royal fire. "There are blue birds ... ... name", this bird is a recorded tree bird. "Oriental way mans, birds body", "North Yujiang, people face birds", the East, the two gods are in the north as a body shape. "Shan Hai Jing" with its many imaginations on the image of the fictional, metamorphosis, the ultimate load of the birds and the ability to foresee the future of the function, to sum up the view, the ancient human existence of a typical animal worship.

Chinese Buddhism in the "Peacock King" worship. The image of the peacock king is generally a four-arm or three-sided brains of the Buddha. Dunhuang Grottoes in the art of peacock Ming Wang roughly covered in the Tang Dynasty, the Five Dynasties, the Song Dynasty three dynasties. Dunhuang Mogao Grottoes murmur in the country has the earliest history, the largest number (eight) of the peacock Ming Wang, respectively, in the Tang Dynasty a (Mo 114 cave), five generations of two (Mo 205,208), the Song Dynasty 5 (Mo 133,165,169,431,456 Cave), the other in Guazhou County, Gansu Yulin 33 Cave, belonging to the Five Dynasties period peacock Ming Wang like. In the middle of the "peacock king and moonlight Buddha" image, the Ming Wang like monk modeling, four arms one, the first set of birds before the blue and white tail around the characters. 
Five generations 205 Mogao Grottoes portrait of the Buddha is the head of the Buddha's majestic female Buddha like. Song of the peacock Ming Wang head wearing a ring, holding the bird feathers and the front of the desire to Teng peacock echoes.

India is a kingdom of God, golden wings and peacocks are regarded as gods. Vishnu (Vishnu) mounts Golden wing birds (buds Luo birds) is known as the first bird. Golden wing birds from Wei Jin to descend into China, it is God's mounts and Buddha's law enforcement. In addition, the peacock was inscribed for the bird king, it was positioned in India's national bird, which is also India's "peacock country" reasons. The history of the fourth century BC, India even appeared in the "Peacock Dynasty". Cattle and peacocks in India to enjoy the status of flirting, both are regarded as gods. Mahayana Buddhism in the law enforcement "Wei pack", Jainism teach ancestral star are all peacock. In addition, the peacock needs to be twice a year due to physiological needs, so the peacock feathers are made into ornaments for peddling.

Japan's crane culture, the original pheasant culture mixed with traditional folk and aesthetic ideas. The original pheasant was designated as a national bird in Japan, Japan's "ancient things", "Japanese book", "million leaves", "Genji story", "seeking ancient map" are described in the cranes. "Ancient things" in the myth of the story also records the domain of God and the interval between the birds and the day according to the gods, the relationship between the original pheasant. A pair of water in the Chinese and Japanese mythology there are gods Chongxin.

Eagle is the symbol of the ancient Egyptian, Sumerian royal family. Agricultural civilization popular ancient Egyptian Nile River ancestors that the sun is the eagle, in charge of the growth of crops, and even the flood of the Nile flood, seasonal changes are associated with the Condor. Eagle in ancient Egypt is considered the patron saint of Pharaoh, the Ptolemy dynasty of the Edfu Temple is dedicated to the offerings of God Osiris and birth of God Eisse son Eagle God Horus, the temple stands outside the Eagle head Of the Eagle Horus sculpture guarding the temple and Pharaoh, after the Egyptian father of Ptolemy 12th after the architectural temples and a little whitewash. By the 1920s and 1930s Art Deco (Art Deco) on the ancient Egyptian tombs unearthed cultural relics, the film "Cleopatra" in the "brilliant" Crete Petra's design has a lot of Golden Eagle Elements of the integration, and then by the impact of film art American Chrysler building also draws on the same elements of the falcons. In addition, the ancient Egyptian mythology there is another kind of bird god worship: Beno bird (immortal bird) Chongxin, this bird is known as the soul of the sun, this bird never disillusioned, is a symbol of spiritual eternity.

Thailand's Dapeng golden winged bird is that Luo Yan King (over the net king) when the patrol ride, the daily time at any time in the king's residence on standby. Dapeng golden wing bird is the Royal Thai law enforcement bird, is the emblem of Thailand, religious architecture in the important Huaying, all the Thai government signed the document will cover the bird seal. Thailand's iconic building in the palace construction in the golden wing bird modeling as a model. Folk private hanging Dapeng gold wings bird chapter is illegal. The Garuda Museum, one of the most sacred museums in Thailand, is unique in Southeast Asia. Golden wings in Asia enjoy a higher status, it is Thailand, Indonesia's national emblem image, Ulaanbaatar's emblem, Tibet's totem.

In the northwestern Indian coast of the indigenous totem pole culture, the wind of the birds is prevalent. Totem pole is not only related to the totem, it can record the ancestral legend and mythical story. The crow is one of the most noble gods in the Indian worship. Indians "crow tribe" in a white eagle, black eagle "eagle clan". Indian Raven is a symbol of the Eagle Totem. Totem Pole God almost all have long and long beak and wings, and even once the displacement to the beast or character.

When humans first knew the world, birds were identified as gods that were necessary to recognize the world. With the change of the times, the original historical and cultural memory is passed down and inspired by the later creative thinking. Before the sprout of scientific humanism, any country has experienced the worship of pan gods and finally identified as the stage of worship of gods, the bird totem culture is only a multicultural level in the pantheon culture. 


\section{The Cultural Image and Social Association of the Birds under the Image of Farming}

The Bird Culture is a realistic manifestation of the income of the ancient ancestors, which is related to the context of the ancestors' survival. Bird culture can be studied as a fulcrum of social culture, because it is associated with many social entity elements, reflecting many historical and cultural phenomena, from the bird culture study can be seen micro-knowledge, see the spotted spot, with the point of view of the bird image and other cultures Association.

Chongri culture and the bird culture: the ancient bird culture is a reflection of the culture of worship, day and birds coexist patterns appear in all kinds of archaeological instruments. The human wings reach the mysterious and invisible heavenly world represented by "rising day" by the soaring winged bird. "Bird" carries a beautiful fantasy of mankind.

Reproductive culture and the bird culture: in Sichuan Liangshan, Guizhou Miao minority areas, ancestors traced themselves "from where" philosophical problems, used to "imagination" to explain the source of the nation's state.

Rice culture and bird culture: from the "grinding mirage and hoe" to "Lei plow farming hoe" and then to "rice rice soup" ancient farming civilization society, "rice and birds" is the ancient people Shun days, self-reliance To carry out a carrier of business means. In the process of "feeding to the ground", the birds played an important supporting role in the rice harvest of human cultivation. The bird's image to explore, in addition to Acura its beautiful shape, the freedom of action, birds both serve the functions of agricultural labor. First, in ancient times, "elephant farmer", "moose racing birds," the farming methods of labor, "Wu Yue Chun" in the "hundred birds in the reservoir", "Historical Records" in the same " Of the narrative, that is, birds in the field to help humans to catch insects, pull grass soil and soil. Second, the birds have a limiting effect on maintaining the balance of the ecosphere, which regulates the density of the animals that are hanged and maintains the organic cycle of the biological chain in the area.

Nomadic culture and eagle bird culture: the eagle bird is the main labor tool for nomadic minorities, from the Khitan, Jurchen, Mongolian to Manchu has been flourishing. Eagle images and eagle pattern decorated in the northern Khitan, Jurchen, Mongolian grassland nation, Manchu Su Shen (ancient northeast) culture can be seen everywhere. The origin of the Mongolian shaman and the existence of the eagle birds, shaman mythology that the eagle is the god of the angel of God, is the protection of the shaman. Shaman God hat on the copper bird is the symbol of the Eagle. Bai Haiqing once became Genghis Khan belongs to begging Yan's ancestral gods. Manchu culture in the sea east is a hawk falcon, it is the highest gods in the culture of God.

Folk culture and "bird bogey": Chong bird is a bird as the ancestors, gods behavior, and the bird is a bird for the evil behavior. "Sheep Division morning" is considered to interfere with the non-profit symbol. Poison wine is made with poison birds feathers made of poison wine, can kill people. "Dove magpie nest" is used to describe people offside and overly greedy. "Nine birds" was once relegated to disaster, ferocious incarnation. For the birds of the call also have the joys and sorrows, the cuckoo sad, the owl whine, crow crow called ... ... birds become a precursor to human foresight disaster.

Bird image and the political, economic, religious, culture, there is a relationship between the branches and relatives. There is a dialectical unity and interdependence between the culture of worship and culture, the culture of nomadic culture and the reproductive culture. There is a bird must exist in the bird, folk culture in the bird taboo is another aspect of bird culture research.

\section{The Broad Pattern: The Establishment and Architecture of Bird Art}

From the ancient literati poet, Danqing craftsmen to contemporary art creation, from art to art of space, from the decoration to the birds to the birds, the bird image outlines a series of ancient and modern "bird era" picture. Bird art image eventually formed a broad pattern, self-contained architecture and inherent evolution of the log system.

Bird image in the art of painting as a basic theme has become a common phenomenon. From the 
traditional flower and bird painting to the contemporary art creation, the bird image is always the theme of painting creation

Northern Song Dynasty garden flowers and birds painting is the peak of the brushwork, is the era of traditional artwork. Song brushwork flower and bird painting features are: life breath enough, sketch marks strong. Song of flowers and birds to "take shape and shift the spirit", "Miao body weight" is known. "Xuan and painting spectrum" recorded Huizong collection of flowers and birds painted 2768, accounting for about half of the total number of collections. In the early days of the Northern Song Dynasty, the "Seiko rich and powerful" of the Huang Quan school unified painting, after a hundred years of circulation and finally lifeless, Cui Bai, Yi Yuanji and then reform, revival $\mathrm{Xu} \mathrm{Xi}$ painting, for some time, on behalf of the royal wealth of Huang Quan Temporarily less than five generations of $\mathrm{Xu} \mathrm{Xi}$ wild Yi sent, but the two factions did not withdraw from the flower and bird painting, so flowers and birds to flourish. LIn addition, Huizong thin body can be described as the world alone, with the post-Li Yu's political destiny and artistic talent similar to the two men are Yan Wu Xiuwen is the so-called "everything cannot be emperor."

In the late Ming and early Qing Dynasty, the image of the bird of the eight mountain people (Zhu Da, 1626 to about 1705) could be called "nameless migratory birds". Li Zu-chan that: "He (eight) neither invented the abstraction of the abstract, do not write the eyes of the appearance, only focused on the intention of Italy." Zhu Da as the royal family through the change of the Ming Dynasty (1644), witnessed the "country of death and the enemy is still in the" melancholy blame, it is difficult to relieve the Manchu iron hoof Ming Ming resentment, suppression of upside down but fled the empty door. His artistic accomplishments made him one of the four monks of the early Qing Dynasty. His birds generally have an independent foot, to the day white eyes, curled neck, gray arch back characteristics. His bird image can be described as "little ink heaven and earth," Buddhist children on the secular interpretation is often transparent, lingering lingering taste. Eight Za Zang and then vulgar, but its painting style is stronger than to avoid the skills of law, Zen artistic conception in the chest, sparse paintings from the epiphany. He used a few pen to outline the outline of the birds, additional water blooming, and ultimately a "independent" Zen birds jumped on paper. Su Shi has a saying, "the painting is really in the subtle" remarks, painting the subtlety of the real mood of the wonderful. Eight birds are good at flowers and birds, the image of birds in particular with their own characteristics, with their paintings "solitary birds", "bird diagram", "Dutch bird", "song bird", "dead wood to poultry", "wicker Starling map "," bird "the most representative. Among them, "solitary bird map" is the eight art classics, is the most expensive contemporary art auction a national painting birds.

In the Qing Dynasty (Kang, Yong, dry years) Hua Yan (1682 1756) is representative of Yangzhou painting school. His "work with the work to write" the birds can be described as "small freehand". He absorbed (Ming) Chen Chun, Zhou of the crown, (Qing) Yun Shouping style of the long, bird image does not lose the meticulous meticulous, not missing freehand Shulang Jane Yi.

Lin Fenmei love "to the birds metaphor", that painting birds is painting, his birds can be "Happy Bird" concept. He painted birds hobby to square composition, different from the traditional composition of traditional Chinese painting composition, with modern painting design means. Lin Fengmian painting in the bird image of natural simple, simple and honest, more rich in life. "Autumn in the starling" because of their childhood memories of the eight brother birds and creative, or gray or black row of birds always smile Yingying, his birds are thousands of sails after his ultra vious intentions, his birds are Is a happy self.

The image of the bird becomes a "free bird symbol" in contemporary art. Ye Yongqing (1958-) created a series of "bird image" fabric of "peacock", "painted bird", "durian branch yellow bird". The bird also became his personal figure and symbolic representation. He thinks his bird is a sign that is not a traditional painting in the sense of the birds. He hoped that the image of the bird was a link between the painter and the reader, in an attempt to view his thoughts and creations through the ladder.

Taiwan to the Qianlong period of the palace painting more than the province, Zhang for the state copy "bird spectrum" as a model, board design issued a "bird" theme to commemorate the stamps. 
The first four volumes were preserved in the Taipei National Palace Museum, while the remaining eight volumes were collected at the Palace Museum. The image of birds is a basic motif of tradition and modern art creation. Birds are the ordinary symbols of artistic creation practice, but the expression of the painting is "benevolent see benevolence", Huizong birds realistic, eight birds freehand, Hua Yan's birds and work to write, Li's bird rate sexual intercourse, Lang Shining bird fine, Lin Fengmian birds happy, Ye Yongqing's bird is a symbol.

Simple theme: different view of the birds under the visual image of the image of identity

Human love birds like the head of the sky. "Bird" is the Eastern and Western sculpture of the favorite theme of the artist. However, artists in different contexts give different interpretations of the recognition and understanding of the same subject matter.

Branchesian abstract sculpture is a modern totem art form. "Bird of the air" sculpture is abstract and minimalist form of interpretation. Romanian sculptor Constantin Brancusi (1876-1957) "Bird in Space" (Bird in Space) is a modern masterpiece of modern sculpture, in the form of a complete breakthrough in the natural figurative entity restrictions. Brancusi had declared: "I whole life is looking for one thing, that is the nature of flying." Branchesi finally established the form of Western abstract sculpture art, his works in the history of sculpture is equivalent to Duchamp's "Spring" works in the contemporary concept of art status. "Bird of the Air" is based on the folklore of Romania: the pure golden feathers indicate a better future and cure blindness. Brancusi exhausted sixteen studies of "space bird", he completed in 1924 the first abstract "bird" works, and in 1940 to form a final work. "The bird of the air" is a bronze material, similar to a feather shape sculpture on the top of the tip and the bottom of the soft, slightly convergent curvature makes the whole piece of work light and smart, works simply introverted and extended rich. "Bird of the Air" will be a shape like a long exclamation mark of the image of the birds to restore the birds like the light simple shape, his bird sculpture is the idea of flying birds to shape, the abstract concept of the body clearly Out, so its shape is not geometric, but contains extreme abstract and subtle symbolic meaning. In the history of modern sculpture, Brancusi can be pushed to a symbol of the mechanical era of avant-garde sculptor.

"Golden Birds" (Golden Bird, 1919-1920) Sculpture Mixed Primitiveism with Extreme Mature Art Forms. "Golden Bird" has an elegant, slim body shape placed on a rough, simple wood substrate above the bird's beak and claws after the merger, simplification and have a general "bird" features or impression. "Rooster" sculpture conveys the true face of its appearance, and the chicken's abdomen is simplified as a zigzag shape and eventually integrated into a straight line that is simplified as a straight line. The shape of the rooster in a simple, rigid geometric lines outlined, more abstract, high mental state.

\section{References}

[1] Zhou Mingchu (school note), "Shan Hai Jing" [M] Hangzhou: Zhejiang Ancient Books Publishing House, 2002

[2] Li bitter "for the source of living water - read the eight mountain painting and calligraphy with the mind" [J] "Art Research", 1979 years 03

[3] [Jin] Guo Pu (with), Li Xueqin (editor) "13 by the sparse" [M] Beijing: Peking University Press, 1999

[4] Sun machine (with), "Chinese ancient service on the board" (updated) [M] Beijing: Cultural Relics Press, 2001

[5] [Qing] Zhang Tingyu, etc. (with) "twenty-four history of history" [M] Beijing: Zhonghua Book Company, 1997

[6] [clear] Qiu Jun (the) "University of justice to fill" [M] Beijing: Jinghua Publishing House, 1999 